\title{
Dimensions of Temperament: Affect Intensity and Consumer Lifestyles
}

\author{
David J. Moore \\ Department of Sport Management and Communication and School of Business Administration \\ University of Michigan \\ Pamela M. Homer \\ Department of Marketing \\ California State University, Long Beach
}

\begin{abstract}
This article focuses on the relation between affect intensity and 3 fundamental dimensions of temperament-emotionality, sociability, and sensory arousability. The purpose was to show that individual differences in affect intensity as a dimension of temperament can influence not only advertising responses, but also the lifestyles and preferences of consumers. Study 1 confirmed the emotionality dimension in that high affect intensity individuals responded with significantly stronger levels of emotion when exposed to an affectively charged advertising appeal, but not when exposed to a nonemotional appeal. Studies 2 and 3 demonstrated that the fundamental dimensions of temperament are accompanied by heightened emotional intensity and do predict different preferences for lifestyle activities for high and low affect intensity consumers. A significant Affect Intensity $\times$ Gender interaction occurred indicating that both men and women expressed stronger emotions when experiencing activities that were gender-congruent (e.g., watching sports on TV for men, and smelling perfumes for women). Future research directions are also discussed.
\end{abstract}

Affect intensity refers to stable individual differences in the strength with which individuals experience both positive and negative emotions (Larsen \& Diener, 1987). The Affect Intensity Measure (AIM; Larsen, 1984) can be used to identify profiles of consumers who might respond more favorably to emotionally charged advertising appeals as opposed to a cognitively oriented nonemotional message. Moore, Harris, and Chen (1995), for example, demonstrated that when participants were exposed to emotional advertising appeals, those who were classified as high in affect intensity manifested significantly stronger emotions to the ad than their low-intensity counterparts. When exposed to nonemotional advertising appeals, however, high and low affect intensity participants did not differ in the magnitude of their emotional response. In addition to these findings, this individual difference construct has the potential to make an even more com-

Requests for reprints should be sent to David J. Moore, Department of Sport Management and Communication, University of Michigan, 1030 CCRB, 401 Washtenaw Avenue, Ann Arbor, MI 48109-2214. E-mail: djmoore@umich.edu prehensive contribution to marketing if researchers investigate not only advertising responses but also the link between affect intensity and other dimensions of consumer behavior such as gender differences, lifestyles, media entertainment choices, and buying preferences. However, the attempt to establish a link between individual difference variables and consumer lifestyle behavior can be quite a challenging task because it requires a strong and compelling theoretical foundation (Bagozzi, 1994; Haugtvedt, Petty, \& Cacioppo, 1992). Prior research has shown that affective response intensity is a stable temperament-like characteristic that covaries with three fundamental dimensions of temperament-activity level, sociability, and emotional reactivity (Larsen, 1984). In other words, critical dimensions of temperament seem to be accompanied by heightened affective responsivity (Larsen \& Diener, 1987). As such, the affect intensity construct, serving as a dominant dimension of temperament, has the potential to be a valid starting point in predicting certain aspects of consumer lifestyle and behavior.

The purpose of this article is to show that individual differences in affect intensity as a dimension of temperament can influence not only advertising responses, but also the life- 
styles and preferences of consumers. First, we present the theoretical foundations of affect intensity and how it differs from other related constructs. Second, we discuss the fundamental dimensions of temperament and their relations to individual differences in affect intensity and related lifestyle activities. Three studies, designed to complement and "build upon" each other, are reported here as evidence of these relationships. Study 1 examines the emotionality dimension of temperament using audience responses to emotional advertising appeals. Study 2 moves beyond advertising appeals and examines the relationships between affect intensity as a dimension of temperament and consumer lifestyle activities. Study 3 is intended to replicate the findings of Study 2 and to investigate the role of gender as a moderating factor between affect intensity and consumer lifestyle behavior.

\section{AFFECT INTENSITY}

\section{Development of the AIM}

The AIM (Larsen, 1984) assesses the strength of the emotions with which individuals respond to affect laden stimuli (Larsen \& Diener, 1987). The scale captures a broad spectrum of positive and negative emotions. Physical sensations normally associated with emotional reactions (e.g., pounding of the heart) are also captured by the scale. It is important to note that the scale items were designed to reflect intensity rather than frequency of emotional reaction. Consequently, there was a conscious attempt to avoid items that might confound frequency with intensity (e.g., "I am happy quite often"). From an original pool of 342 items, a series of factor analyses was performed resulting in a final scale with five intercorrelated underlying dimensions. These five factors are all associated with specific domains of both positive and negative emotional reactivity (Larsen, 1984). The titles of the factors, accompanied by an example of one of the highest loading items, are listed here (Larsen, 1984, p. 80):

1. Intrapersonal Positive Affect (e.g., "When I'm happy I feel like I'm bursting with joy")

2. Preference for Arousal (e.g., "When I'm happy it's a feeling of being untroubled and content rather than being zestful and aroused")

3. General Intensity (e.g., "I can remain calm even on the most trying days" [reversed])

4. Intrapersonal Negative Affect ("When I feel guilty this emotion is quite strong")

5. Reactivity to Positive Events ("If I complete a task I thought was impossible, I am ecstatic").

Assessments of the intercorrelation of the AIM revealed alpha coefficients in the range of .90 to .94 across four separate samples, whereas test-retest reliabilities were $.80, .81$, and .81 over 1-, 2-, and 3-month intervals, respectively
(Larsen \& Diener, 1987). The validity of the AIM was determined by a multimethod approach - the use of parental reports and peer reports of the participants' emotional intensity. Parents' report of emotional intensity exhibited by their children correlated .50 with the AIM, whereas peer reports correlated .41 with the participants' self-report of affect intensity (Larsen \& Diener, 1987). Thus, it seems that the AIM is a somewhat reliable and valid estimate of the intensity with which individuals experience their emotions.

\section{Affect Intensity and Arousal Regulation}

Early theorists have attempted an explanation for individual differences in response to sensory arousal (Berlyne, 1960; Fiske \& Maddi, 1961; Hebb, 1955). More recently, Strelau (1982) suggested that sensory stimulation is regulated by an internal modulation mechanism that augments the intensity of stimulation experienced by people with certain types of temperaments and minimizes the force of that stimulation for others (Barnes, 1976; Petrie, 1967). Accordingly, the individual who reacts to incoming stimuli by reducing the intensity will be relatively underaroused, whereas the augmenter-type individual will be relatively overaroused. Underaroused individuals should thus be expected to show a higher need for more intense forms of sensory stimulation, whereas the overaroused individuals will be motivated to minimize the exposure to sensory stimulation (Barnes, 1976; Larsen \& Diener, 1987). Based on the strong relation between average daily arousal levels and emotional response intensity, Larsen (1984) suggested that persons high in affect intensity are "arousal hungry" in the sense that they maintain higher average daily levels of arousal than low affect intensity persons.

\section{DISTINGUISHING AFFECT INTENSITY FROM OTHER CONSTRUCTS}

\section{Optimum Stimulation Level (OSL) of Arousal}

Because the concept of arousal regulation provides the theoretical underpinning for affect intensity (Barnes, 1976; Larsen \& Diener, 1987), it seems worthwhile to point out the distinctions between affect intensity and other constructs such as OSL, which is very similar to the notion of arousal regulation. This OSL concept has been utilized as a personality trait to predict consumer behavior (Raju, 1980; Steenkamp \& Baumgartner, 1992). OSL theorists assert that when environmental stimulation (derived from experiences such as novelty, ambiguity, and complexity) falls below a desired level, the individual will become motivated to increase the level of arousal; conversely, when the stimulation level rises above the optimum level, the individual will be motivated to reduce it (Hebb, 1955; Maddi, 1989). Raju (1980), for example, found that consumers with 
high and low OSL scores showed significant differences with respect to risk taking, innovativeness, brand switching, and proneness to repetitive behavior (see also Steenkamp \& Baumgartner, 1992). Despite the apparent similarity of the concepts of arousal regulation (Strelau, 1982) and OSL (Hebb, 1955 ), the AIM was found to be uncorrelated, $r=.019, p<.89$, with the Raju (1980) OSL scale (Homer \& Moore, 1998). Affect intensity has therefore exhibited sufficient discriminant validity when compared to the OSL construct, which does not measure individual differences in the intensity of an emotional experience, but other unrelated behaviors such as proneness to risk taking, innovation, and brand switching.

\section{Affect Intensity and Sensation Seeking}

Larsen, Diener, and Emmons (1986) reported that affect intensity showed a zero correlation with Zuckerman's (1979) Sensation Seeking Scale. The reason is that, unlike the affect intensity construct that measures affective reaction to normally occurring day-to-day activities, sensation-seeking incorporates behaviors associated with risky and thrilling activities that are unusual and infrequent and serve to provide a change from the daily routine of life (Larsen \& Diener, 1987). High-intensity individuals tend to maintain strong and consistent emotional arousal by engaging in those day-to-day activities most likely to stimulate emotions. In other words, "individuals high on the affect intensity dimension do not seek out-of-the-ordinary experiences as much as they seek out an ordinary daily life that is more emotionally stimulating" (Larsen \& Diener, 1987, p. 24).

\section{Affect Intensity as Temperament, Not Personality}

Larsen and Diener (1987) contended that affect intensity can be more appropriately characterized as a temperament construct rather than a personality trait. Personality, it is argued, is linked to a consistent pattern in the content of one's behavior, whereas temperament is a representation of consistencies in the style of the behavior exhibited by the individual (Strelau, 1982). Thus, personality might be construed as what a person does (content), whereas temperament might be construed as how a person does it - the manner (style) in which an individual displays certain behaviors (see also Digman \& Shmelyov, 1996; Halvorson, Kohnstamm, \& Martin, 1994; Maddi, 1989). For example, when a person is classified as high on the Richins (1992) materialism scale, it means that the content of that person's behavior is consistent with materialistic values and attitudes. However, people might differ significantly in the manner (i.e., the style) with which they actually acquire their materialist possessions. Some people's style of acquisition might be described as overtly persistent, deliberate, and methodical, whereas others might attempt to acquire their possessions at a frantic and vigorous pace. The uniqueness in the difference in these two styles of behavior (persistent and deliberate vs. frantic and vigorous) is what one can appropriately identify as the difference in the temperamental characteristic of activity level (Larsen \& Diener, 1987). Affect intensity can therefore be classified as a dimension of temperament because the style (high vs. low emotional intensity) with which an individual responds to stimuli or experiences in daily living might be manifested across a wide spectrum of emotions in a variety of life situations (Larsen et al., 1986).

\section{Fundamental Dimensions of Temperament}

Based on earlier research on energy arousal regulation and temperamental characteristics (Buss \& Plomin, 1975; Strelau, 1982; Thomas, Chess, \& Birch, 1970), Larsen (1984) proposed four fundamental dimensions of temperament: (a) Emotionality - the intensity with which the individual is aroused by negative or positive emotional stimuli; (b) Sociability - the extent to which the individual responds to, or seeks out, emotional stimulation from the companionship of others; it represents a style of social responsiveness (Buss \& Plomin, 1975); (c) Sensory Arousability - the extent to which the individual tends to be easily aroused by sensory stimuli (this dimension of temperament relies on the Mehrabian, 1979, concept of arousability, which identifies individuals who are overly sensitive to sensory stimulation such as olfactory sensitivity, auditory sensitivity, tactile sensitivity, and thermal sensitivity); and (4) Activity Level - the extent to which the individual displays a high or low level of energy. Larsen (1984) emphasized that these temperamental characteristics serve as a means of regulating arousal level. Because this arousal regulation function has also been associated with affect intensity (Barnes, 1976; Larsen \& Diener, 1987), it might be predicted that individual differences in affect intensity should covary with the basic dimensions of temperament (Larsen, 1984, p. 58).

\section{Relation of Affect Intensity to Dimensions of Temperament}

Larsen et al. (1986) found a significant relation between affect intensity and temperament using standard inventory measures of emotionality, sociability, sensory arousability, and activity level. Their findings seem to suggest that having a relatively high level of affect intensity might be associated with having high scores on each of the four dimensions of temperament (Larsen \& Diener, 1987). In other words, people who have elevated scores on the AIM might also (a) manifest a greater tendency to be emotionally reactive, (b) have a high need for social stimulation, (c) display a high level of sensitivity to sensory stimulation, and (d) tend to be more 
physically arousable. In another related study, Larsen et al. (1986) examined the link between affect intensity and people's response to naturally occurring activities in daily life. Each item on a checklist of 28 common activities was rated on the basis of its potential for evoking an emotional reaction from a typical human being. Activities were rank-ordered from the most emotionally provocative (sexual activity) to the least emotionally provocative (writing letters). Participants in a 2-week panel study recorded each time they engaged in any of the identified activities. The results indicated a significant correlation between affect intensity and the tendency to engage in emotion-producing activities, $r=.42, p<$ .01 ; that is, high affect intensity participants were more sociable, more physically arousable, more active, and more emotionally reactive than their low affect intensity counterparts.

This article examines the extent to which three important dimensions of temperament are significantly related to various elements of consumer behavior. Study 1 shows the relation between affect intensity and the emotionality dimension of temperament. Studies 2 and 3 illustrate how three dimensions of temperament (emotionality, sociability, and sensory arousability) are related to consumer lifestyle behavior.

\section{STUDY 1}

Study 1 explores the emotionality dimension of temperament in the context of consumers' responses to affectively charged advertising appeals. In this study we address three specific issues related to affect intensity: (a) emotional reactions to advertising appeals, (b) ad enjoyment, and (c) empathic emotional involvement.

\section{Emotional Responses}

Prior studies have shown than when consumers are exposed to either a positive or negative emotional advertising appeal, the emotions expressed by high affect intensity consumers were significantly stronger than the emotions expressed by low affect intensity consumers. In contrast, when respondents were shown a nonemotional advertising appeal, there were no significant differences in the intensity of emotions expressed by high versus low affect intensity individuals (Moore, 1995; Moore et al., 1995).

\section{Ad Enjoyment}

If high affect intensity individuals experience their emotions with greater strength, it is logical to predict that these individuals will report less enjoyment of a negative emotional advertising appeal than their low-intensity counterparts. If this is so, there might be important advertising implications. For example, some broadcast audiences might manifest an avoid- ance and a distaste for high-impact emotional advertising messages. This might lead not only to a negative attitude toward the ad but also a tendency to "zap" and skip over to more pleasant broadcast programming (Moore \& Harris, 1996).

\section{Empathic Emotional Involvement}

The concept of affect intensity accommodates the notion that strong emotions might also be manifested in a variety of ways. Therefore, the evaluation of an emotional experience as well as the thoughts used to describe that experience might reflect greater empathic involvement on the part of high-intensity individuals (Larsen, Billings, \& Cutler, 1996; Moore, 1995). Consistent with this notion, Moore found that high-intensity respondents did experience (a) deeper levels of empathic involvement in the drama depicted in the ads, (b) a stronger identification with the actor featured in the ad, and (c) a greater understanding of the central issues presented in the ad. More important, if high-intensity individuals do experience their emotions with stronger intensity, it should be expected that exposure to a high-impact negative emotional advertising appeal will be a more painful experience for the high affect intensity respondents than for their low-intensity counterparts (Moore, 1995).

This study, unlike other experiments, uses radio instead of television advertising appeals. Only one feature of the ad will be manipulated - the presence or absence of affect-producing sound effects. For all three hypotheses, no significant differences in affect intensity scores are predicted to occur in response to the nonemotional ad. Compared to their low-intensity counterparts, it is predicted that high-intensity participants, when exposed to the emotional ad, will (a) manifest stronger emotional reactions, (b) display a greater tendency to engage in a pattern of thoughts showing empathic involvement, and (c) perceive the exposure to the ad to be a more painful experience and thus report less ad enjoyment.

\section{Method}

\section{Participants and Experiment Design}

Participants were 332 undergraduates ranging in ages from 19 to 24 years. The experiment featured a $2 \times 2$ (High vs. Low Affect Intensity $\times$ Emotional vs. Nonemotional) between-subjects factorial design.

\section{Stimuli}

Two radio ads representing the emotional and nonemotional versions of an advertisement for a new brand of burglar alarm were professionally prepared. The advertising copy was read by an announcer for the National Public Radio 
affiliate at The University of Michigan. Ads in both test conditions contained the same message text and were similar in length. The ads emphasized the need to protect the home from burglars by purchasing the Safety Sentry (a fictitious brand) burglar alarm system. The script for the nonemotional version was as follows:

Protect your home and your loved ones. Burglars can commit violent crimes. Get the Sentry Alarm from Honeywell. Safety Sentry is affordable, easy to install and can be turned on and off by remote control. Safety Sentry comes with a loud built-in power horn alarm and senses intruders by detecting body heat and motion. Safety Sentry is available at all major hardware stores.

The ad copy for the emotional version was the same except that the ad was introduced by an 8-year-old boy who was home alone when a burglar attempted to break in. Appropriate sound effects depicting a break-in and the cries for help by the child could be heard in the background. In essence, the only feature that differentiated the two versions of the ads was the sound effects that were designed to evoke feelings of concern and compassion and a realization of the need to purchase a burglar alarm system.

\section{Procedure}

Phase One. From their responses $(N=332)$ to the AIM, participants in the upper and lower quartiles (scores ranging from 85 to 146 and from 171 to 209 , respectively) were selected and invited to participate in a new study scheduled to take place 3 weeks later. A total of 91 participants, all White (62\% women), participated in this second phase of the experiment.

Phase Two. Participants were informed that the study was part of a comprehensive research program to determine how consumers feel about game shows on radio. Participants were preclassified as either high or low in affect intensity and were randomly assigned to one of the two ad-type conditions. Each session contained 5 to 7 participants who were invited to listen to a radio version of a TV game show. At the end of the third commercial break during the show, participants were exposed to the target ad. Following this, participants were asked to turn to their questionnaires to record their feelings and thoughts.

\section{Measures}

Emotional responses. A combination of empathic and negative emotions measured on a 7-point scale was used to measure emotional response to the ad (Batra \& Holbrook, 1990; Davis, 1983; Izard, 1977). Adjectives used were: touched, sympathetic, compassionate, sad, worried, and bored.

Empathic emotional involvement. Seven items were used to determine the extent to which participants were emotionally and empathetically involved or "drawn into" the processing of the advertising appeal (see Table 1). Items used were based on prior work by Stiff, Dillard, Somera, Kim, and Sleight (1988) and Stout and Leckenby (1986).

Ad Enjoyment was measured by two 7-point agree or disagree scales: "It was painful for me to listen to this ad," and "I enjoyed listening to this ad" (Moore \& Harris, 1996).

Manipulation checks. The objectives of the manipulation checks were to (a) determine whether respondents perceived the two respective versions of the target ads to be emotional versus nonemotional in nature and (b) ascertain whether factors other than the intended manipulations of the stimuli might have had an unexpected influence on participants' responses to the ads. The four items were measured on 7-point scales: (a) "This ad had a strong appeal to my emotions," (b) "This ad contains specific factual information," (c) "This ad grabs my attention," and (d) "This ad is interesting."

TABLE 1

Emotional and Emphatic Thoughts as a Function of Affect Intensity and Ad Type

\begin{tabular}{|c|c|c|c|c|}
\hline \multirow[b]{2}{*}{ Measure } & \multicolumn{2}{|c|}{ Affect Intensity } & \multicolumn{2}{|c|}{ Ad Type } \\
\hline & High & Low & Emotional & Nonemotional \\
\hline I felt I was right there in the ad experiencing what the actor was feeling. & 4.21 & $3.31^{* *}$ & 4.67 & $2.56^{* * * *}$ \\
\hline The ad made me think about the negative consequences of not having a burglar alarm. & 5.16 & $4.11 * * *$ & 5.51 & $3.44 * * * *$ \\
\hline The ad tended to evoke within me a desire to offer help or protection to the actor. & 4.06 & $3.24^{*}$ & 4.78 & $2.18 * * * *$ \\
\hline The ad made me feel a bit fearful about what could happen if an intruder breaks into a house. & 4.89 & $4.12^{*}$ & 5.53 & $3.20 * * * *$ \\
\hline This ad caused me to have feelings of anger toward burglars. & 3.97 & 3.37 & 4.55 & $2.56 * * * *$ \\
\hline It was painful for me to listen to this ad. & 2.48 & $1.70^{* * *}$ & 2.69 & $1.23 * * * *$ \\
\hline I enjoyed listening to this ad. & 1.63 & 1.85 & 1.83 & 1.67 \\
\hline
\end{tabular}

Note. $\quad N=91$.

${ }^{*} p=.05 .{ }^{* *} p=.01 .{ }^{* * *} p=.001 .{ }^{* * * *} p=.0001$ 
Results

\section{Manipulation Checks}

Analysis of variance (ANOVA) results showed that, compared to the nonemotional appeal, the emotional version was perceived to be (a) more appealing to the emotions $(M \mathrm{~s}=4.69$ vs. 2.16), $F(1,91)=26.54, p<.0001$; (b) more attention-grabbing in nature $(M \mathrm{~s}=5.89$ vs. 3.23$), F(1,91)=53.55, p<$ .0001 ; and (c) more interesting ( $M \mathrm{~s}=5.12$ vs. 2.97$), F(1,91)$ $=39.82, p<.0001$. These findings are consistent with our expectations for the manner in which an emotionally charged advertising appeal would influence a message recipient. However, it was also important to demonstrate that despite the emotional/nonemotional manipulations of the stimulus, both ads should be perceived as containing equivalent amounts of information. The results showed that the emotional ad was viewed as only marginally more informative than the nonemotional ad $(M \mathrm{~s}=3.63$ vs. 3.00$), F(1,91)=$ $2.90, p<.09$.

\section{Dependent Measures}

Emotional responses. Table 2 shows the results of an ANOVA featuring six emotional response measures. The predicted Affect Intensity $\times$ Ad-Type interactions were observed. For example, when participants were exposed to the emotionally charged advertising appeal, high-intensity individuals responded with significantly greater emotional intensity than did their low-intensity counterparts. There were significant main effects for affect intensity and for ad-type on five emotions (touched, sympathetic, compassionate, sad, worried). As predicted, when participants were exposed to a nonemotionally charged appeal, high and low affect intensity participants did not differ in the level of their responses on the five emotions. For the measure of boredom, there was no affect intensity main effect. When asked whether they felt bored by the nonemotional ad, both high and low affect intensity participants showed no significant differences. However, an ad-type main effect was observed, in that the emotional ad was rated as less boring than the nonemotional ad $(M s=2.87$ vs. 4.22 , respectively), $F(1,91)=14.74, p<.0001$. Interestingly, the Affect Intensity $\times$ Ad-Type interaction showed that in response to the emotional ad, it was the low-intensity participants who felt more bored than the high-intensity participants $(M \mathrm{~s}=3.21$ vs. 2.42$), F(1,91)=3.57, p<.05$. Conversely, when the ad was nonemotional, it was the high-intensity participants who showed a marginal tendency to be more bored than their low-intensity counterparts $(M \mathrm{~s}=$ 4.88 vs. 4.12$), F(1,91)=3.57, p<.06$.

Empathic emotional involvement. Table 1 shows the ANOVA means associated with the six items used to measure the extent to which high- and low-intensity respondents tended to be emotionally involved with the ad and to express feelings of empathy toward the actor. In general, although there were significant main effects for the affect intensity and for the ad-type variables, only one measure revealed a significant Affect Intensity $\times$ Ad-Type interaction. In response to the first measure ("I felt I was right there in the ad experiencing what the actor was feeling"), high-intensity individuals scored significantly higher than their low-intensity counterparts $(M s=4.21$ vs. 3.31$), F(1,91)=5.43, p<.02$. A significant ad-type main effect also occurred, in that participants who were exposed to the emotional ad showed more empathic emotional involvement than those exposed to the nonemotional ad $(M \mathrm{~s}=4.61$ vs. 2.56$), F(1,91)=30.28, p<$ .0001 . The second item ("The ad made me think of the negative consequences of not having a burglar alarm") also showed significant main effects for affect intensity, $F(1,91)$ $=13.28, p<.005$, and for ad-type, $F(1,91)=31.66, p<.0001$. Similar main effects were observed for the third and fourth items. However, for the fifth item (" $\ldots$ feelings of anger toward burglars"), there was a main effect only for the ad-type variable, $F(1,91)=23.92, p<.0001$.

Ad enjoyment. For the sixth item ("It was painful for me to listen to this ad"), there were main effects for affect in-

TABLE 2

Emotions as a Function of Affect Intensity and Ad Type

\begin{tabular}{|c|c|c|c|c|c|c|c|c|c|}
\hline \multirow[b]{3}{*}{ Measure } & \multirow{2}{*}{\multicolumn{2}{|c|}{ Affect Intensity }} & \multirow{2}{*}{\multicolumn{2}{|c|}{ Ad Type }} & \multicolumn{5}{|c|}{ Affect Intensity $\times$ Ad Type } \\
\hline & & & & & \multicolumn{2}{|c|}{ High Affect Intensity } & \multicolumn{2}{|c|}{ Low Affect Intensity } & \multirow[b]{2}{*}{$F$} \\
\hline & High & Low & Emotional & Nonemotional & Emotional & Nonemotional & Emotional & Nonemotional & \\
\hline Touched & 2.87 & $2.32^{*}$ & 3.31 & $1.67 * * * *$ & 4.09 & 1.35 & 2.71 & 1.88 & $9.15^{* * *}$ \\
\hline Sympathetic & 3.87 & $3.16^{*}$ & 4.67 & $2.05 * * * *$ & 5.48 & 1.88 & 4.07 & 2.16 & $6.08^{* *}$ \\
\hline Compassionate & 3.63 & $2.79 * *$ & 4.10 & $2.03^{* * * *}$ & 5.00 & 1.94 & 3.42 & 2.08 & $6.03^{* *}$ \\
\hline Sad & 2.53 & $1.85^{* *}$ & 2.81 & $1.33^{* * * *}$ & 3.67 & 1.12 & 2.18 & 1.48 & $10.85^{* * *}$ \\
\hline Worried & 3.92 & $3.13^{*}$ & 4.30 & $2.48^{* * * *}$ & 4.86 & 2.76 & 3.89 & 2.28 & 0.37 \\
\hline Bored & 3.52 & 3.64 & 2.87 & $4.28 * * * *$ & 2.42 & 4.88 & 3.21 & 4.12 & $3.57^{*}$ \\
\hline
\end{tabular}

Note. $N=91$.

${ }^{*} p=.05 .{ }^{* *} p=.01{ }^{* * *} p=.001 .{ }^{* * * *} p=.0001$. 
tensity, $F(1,91)=9.66, p<.002$, and for ad-type, $F(1,91)=$ $37.05, p<.0001$, and an AIM $\times$ Ad-Type interaction, $F(1,91)$ $=11.6, p<.001$. As predicted, when the ad was emotional, high-intensity participants found it more painful to listen to the message appeal than did the low-intensity respondents $(M \mathrm{~s}=3.52$ vs. 2.07). However, in response to the nonemotional ad, the significant difference between highversus low-intensity respondents disappeared $(M \mathrm{~s}=1.10 \mathrm{vs}$. 1.30). The response by high- and low-intensity participants to the seventh item ("I enjoyed listening to this ad") was also consistent with these findings, in that high-intensity individuals did not enjoy listening to the ad any more than their low-intensity counterparts, $F<1$.

\section{Discussion}

The results showed that individual differences in affect intensity were significantly related to the emotionality dimension of temperament. Using radio ads, our findings confirmed the validity of previous TV ad studies, in that high-intensity individuals responded with significantly stronger levels of emotion when exposed to the affectively charged advertising appeal. However, these differences remained nonsignificant when similar participants were exposed to the nonemotional appeal (Moore et al., 1995).

Another important finding relates to the higher levels of empathic emotional involvement experienced by high affect intensity participants. Presumably, because of this deeper emotional involvement, high-intensity respondents reported significantly more emotional pain and discomfort when exposed to the emotional ad as compared with the nonemotional ad. This finding is consistent with previous results related to the same measure (Moore \& Harris, 1996). Given the apparent consistency in these findings, future research should examine the possibility that high-intensity individuals might display less tolerance for the repetition of high-impact negative advertising appeals. Hence, advertising "wear-out" should occur earlier for high-intensity participants than for their low-intensity counterparts. One sobering aspect of these results is the fact that there were fewer Affect Intensity $\times$ Ad-Type interactions reported in Table 1 than in Table 2. Note that the issues measured in Table 1 are very relevant to consumer behavior (see, e.g., items such as "The ad made me think about the negative consequences of not having a burglar alarm"). More research is therefore needed to establish the link between affect intensity as an individual difference measure of temperament and critical indexes of consumer behavior.

The findings of Experiment 1 are limited to the impact of affect intensity on consumer response to advertising appeals. However, there is an obvious need to go beyond advertising effects and to determine whether there is a theoretical link between affect intensity and readily observable patterns of behavior such as a person's lifestyle. We believe the concept of arousal regulation that serves as the theoretical underpinning for the affect in- tensity temperament construct has the potential for explaining certain aspects of consumer lifestyle behavior.

\section{STUDY 2}

Unlike previous studies linking personality traits based on OSL typologies to consumer behavior (Raju, 1980; Steenkamp \& Baumgartner, 1992), Study 2 focuses on areas of behavior and lifestyles that are hypothesized to be theoretically linked to basic dimensions of temperament (emotionality, sociability, arousability). Several theorists have suggested that these temperament characteristics function primarily to regulate arousal (Eysenck, 1967; Strelau, 1982). In fact, this arousal regulation function is presumed to be the underlying mechanism responsible for individual differences in affect intensity (Larsen \& Diener, 1987). Accordingly, Study 2 hypothesizes that high-intensity individuals should show a greater tendency to seek out the requisite arousal from day-to-day activities that promote emotional, social, and sensory stimulation (Larsen et al., 1986).

\section{Method}

\section{Participants}

Participants were 328 undergraduates aged 19 to 25 years who responded to the AIM and a battery of lifestyle measures in exchange for academic credit. Upper (scores $>160$ ) and lower (scores < 136) quartiles were used to select the high $(N$ $=88)$ and low $(N=86)$ affect intensity participants. Because the two middle quartiles were omitted from the data analysis, the final sample size was 174 .

\section{Procedure}

Data were collected as part of a larger participant screening program. In the experimental room, participants used a 9-point scale to indicate the extent to which they enjoyed specific lifestyle activities, sensory arousing activities, social activities, and TV and radio programs. The selection of the questionnaire items corresponded with three dimensions of temperament-emotionality, sociability, and sensory arousability. After completing the questionnaire, participants were awarded participation credits and dismissed.

\section{Results}

\section{Emotionality Dimension of Temperament}

Table 3 shows that high-intensity individuals reported significantly stronger levels of enjoyment for emotionally stim- 
TABLE 3

Correlation Coefficients and Cell Means of AIM and Lifestyle Activity Correlates Associated With Emotional Intensity (Study 2)

\begin{tabular}{|c|c|c|c|}
\hline Lifestyle Measure & Correlation With AIM & High AIM & Low $A I M$ \\
\hline 1. Movies with drama and romance & $.41^{* * * *}$ & 6.76 & $5.80^{* * * *}$ \\
\hline 2. Watching soap operas & $.18^{* * *}$ & 5.63 & $4.12 * * *$ \\
\hline 3. Exciting movies at the cinema & $.23 * * * *$ & 7.98 & $7.27 * * *$ \\
\hline 4. Watching comedies on TV & $.15^{* * *}$ & 8.31 & $7.87^{*}$ \\
\hline 5. Scary rides at amusement parks & $.09^{*}$ & 7.42 & $7.00^{*}$ \\
\hline 6. Watching horror movies & -.02 & 5.77 & 5.96 \\
\hline 7. Listening to news on the radio & -.009 & 5.20 & 5.11 \\
\hline 8. Watching TV game shows & -.03 & 4.64 & 4.63 \\
\hline 9. Watching talk shows on TV & $-.20 * * *$ & 3.62 & $4.72 * * *$ \\
\hline 10. Singing and dancing & $.29 * * * *$ & 7.63 & $5.55^{* * * *}$ \\
\hline 11. Eating at restaurant with friends & $.35 * * * *$ & 8.37 & $7.17 * * * *$ \\
\hline 12. Partying with friends & $.17^{* * *}$ & 7.77 & $7.06 * * *$ \\
\hline 13. Entertainment shows with friends & $23^{* * * *}$ & 8.01 & $7.09 * * * *$ \\
\hline 14. Reading quietly and leisurely & .11 & 3.76 & 4.02 \\
\hline 15. Bike riding alone & .04 & 4.64 & 4.79 \\
\hline 16. Jogging alone & -.08 & 5.66 & 6.06 \\
\hline 17. Grocery shopping & $.17^{* * *}$ & 5.47 & $4.44^{* * *}$ \\
\hline 18. Smelling aroma of fresh bread & $.18^{* * *}$ & 6.62 & $5.87^{*}$ \\
\hline 19. Smelling fragrance of perfumes & $23 * * * *$ & 7.17 & $6.03 * * * *$ \\
\hline
\end{tabular}

Note. $\quad N=332$. AIM $=$ Affect Intensity Measure.

${ }^{*} p<.05 .{ }^{* *} p<.01 .^{* * *} p<.001 .{ }^{* * * *} p<.0001$.

ulating activities such as movies with drama and romance $(M s=6.76$ vs. $5.80, p<.0001)$, soap operas, exciting movies at the cinema $(M \mathrm{~s}=7.78 \mathrm{vs} .7 .27, p<.001)$, TV comedies $(M \mathrm{~s}$ $=8.31$ vs. $7.87, p<.06)$, and scary rides at amusement parks $(M \mathrm{~s}=7.42$ vs. $7.00, p<.05)$. There were no significant individual differences in affect intensity in emotional response to media programs such as to news on radio, TV game shows, and TV talk shows, which typically stimulate more cognitive effort than emotional reactivity.

\section{Sociability Dimension}

It was predicted that high-intensity participants would be more likely to enjoy those activities that provide opportunities for social interaction. As predicted, high-intensity participants had a stronger preference for singing and dancing $(M s=$ 7.63 vs. $5.55, p<.0001)$, eating out at restaurants with friends $(M \mathrm{~s}=8.37$ vs. $7.17, p<.0001)$, partying with friends $(M \mathrm{~s}=$ 7.77 vs. $7.06, p<.001$ ), and attending entertainment shows with friends $(M s=8.01$ vs. $7.09, p<.0001)$. Interestingly, we found that activities requiring no social interaction, such as reading quietly, bike riding alone, and jogging alone, did not produce significant differences in affect intensity. This lends support for the sociability dimension of temperament, in that heightened levels of affect intensity were not present when the activity did not satisfy the need for social interaction.

\section{Sensory Arousability Dimension}

As expected, high-intensity participants showed significantly higher levels of enjoyment of arousal produced by sen- sory stimuli such as smelling the aroma of freshly baked bread $(M \mathrm{~s}=6.62 \mathrm{vs} .5 .87, p<.05)$ and the fragrance of exquisite perfumes $(M \mathrm{~s}=7.17$ vs. $6.03, p<.0001)$. High-intensity respondents also reported greater enjoyment for grocery shopping. Apparently, when asked to rate how much they enjoyed grocery shopping, participants focused on the sensory arousing aspects of that task (e.g., smelling and looking at freshly baked goods in the bakery section, or tasting food samples), rather than the more cognitively stimulating aspects associated with a trip to the grocery store (e.g., selecting canned goods and nonfood items). This explanation is speculative and deserves to be tested more extensively in future studies.

\section{Discussion}

Even though the results have shown that affect intensity is significantly related to the major dimensions of temperament (Larsen, 1984), the reliability of these results will be more convincingly enhanced if these findings can be replicated in another study under similar experimental conditions. Some issues are yet to be resolved. For example, concerning the emotionality dimension of temperament, the results indicated that the difference in enjoyment levels for high versus low affect intensity participants was almost marginal $(p<.05)$; moreover, for horror movies, an activity that consumers seek out to experience the thrill of intense fearful, scary sensations, there was no difference in the response scores for high- versus low-intensity respondents. The correlation with the AIM was even negative. If high-intensity individuals experience these emotional sensations (horror and fear) with greater depth, 
then the negative correlation with Affect Intensity and the lack of significance in the scores of high-versus low-intensity participants is consistent with the theory. Replication of these findings in Study 3 will bolster the reliability of the results. With respect to the sociability dimension, it is necessary to confirm whether activities that offer limited opportunity for social stimulation (such as biking alone and jogging alone) will be significantly less attractive to high-intensity participants, as we have seen in Study 2.

\section{STUDY 3}

The purpose of Study 3 was to reconfirm some of the findings observed in Study 2 and to determine whether a relevant demographic variable like gender will provide more illuminating insight into the relation between affect intensity and the dimensions of temperament. Previous research suggests that women tend to score higher on the AIM than do men (Bagozzi \& Moore, 1996; Diener, Sandvik, \& Larsen, 1985), thus prompting the prediction that women will respond with stronger levels of emotion on all dimensions of temperament. Only key measures from Study 2 were used, and two new measures related to sport activities were also included.

\section{Participants and Procedure}

Participants were 915 undergraduates whose ages ranged from 19 to 26 years. Participants were administered the AIM and various lifestyle measures. Using upper (scores $>160$ ) and lower (scores < 136) quartiles of all respondents' scores, analyses were conducted with 286 low- and 255 high-intensity participants. Altogether, there were 314 men and 227 women.

\section{Results}

Table 4 shows the results of a $2 \times 2$ (High vs. Low AIM $\times$ Male vs. Female) ANOVA design. The sizes for the four cells are: High Affect Intensity male = 111, Low Affect Intensity male $=203$, High Affect Intensity female $=144$, Low Affect Intensity female $=81$.

\section{Emotionality Dimension}

Consistent with the results of Study 2, high-intensity participants experienced stronger levels of enjoyment of emotional and romantic activities such as exciting movies $(M \mathrm{~s}=$ 8.80 vs. $7.76, p<.0001)$, romantic emotional music $(M \mathrm{~s}=$ 7.07 vs. $5.27, p<.0001)$, and going on a date $(M \mathrm{~s}=8.65 \mathrm{vs}$. $7.37, p<.0001)$. Of these activities, only romantic emotional music showed a main effect for gender with women scoring higher than men $(\operatorname{men}=5.38$ vs. women $=7.16 ; p<.0001)$. No interactions were observed. High-intensity participants also showed greater enjoyment for other forms of positive emotional experiences such as attending a major sporting event $(M \mathrm{~s}=8.07$ vs. $7.59, p<.0001)$ and watching exciting sports on TV $(M \mathrm{~s}=7.18$ vs. $6.89, p<.0001)$. Notice the Affect Intensity $\times$ Gender interaction effect for these two sports-activity measures, indicating that it was high-intensity men rather than women who expressed greater enjoyment for the emotional stimulation derived from attending a sporting event $(\mathrm{men}=8.29 \mathrm{vs}$. women $=7.15 ; p<.0001)$ and watching exciting sports on TV (men $=7.68$ vs. women $=6.12 ; p<$ $.0001)$. In the case of thrilling and adventurous emotional stimulation, high-intensity participants scored significantly higher for enjoyment of "scary rides at amusement parks" $(M s=7.40$ vs. $6.73, p<.001)$, thus replicating the findings of Study 2 . High-intensity respondents also showed a higher preference for "watching horror movies" $(M \mathrm{~s}=5.05$ vs. 4.58 , $p<.001$ ), a finding that is more consistent with arousal regulation theory (Strelau, 1982). In both of these cases, there were significant gender main effects with men scoring higher than women. In contrast to these emotionally provocative activities, a more cognitive experience like "listening to news on radio" produced no significant differences between highand low-intensity respondents, thus replicating the findings of Study 2. Interestingly, men enjoyed this activity more than women $(\operatorname{men}=5.11$ vs. women $=4.61 ; p<.001)$.

\section{Sociability Dimension}

As predicted, five measures from Study 2 replicated successfully in Study 3. Main effects for affect intensity were observed for "partying with friends" $(M \mathrm{~s}=8.48$ vs. $7.63, p<$ $.0001)$, "singing and dancing" $(M \mathrm{~s}=7.56 \mathrm{vs.} 5.66, p<.0001)$, and "eating out with lots of friends" ( $M \mathrm{~s}=8.76 \mathrm{vs.} 7.66, p<$ $.0001)$. Women scored significantly higher than men in all three measures. Consistent with Study 2, there were no significant affect intensity differences for mild social interaction activities such as "reading quietly and leisurely" and "bike riding alone." For the "reading quietly" measure, women reported a higher level of enjoyment. Contrary to expectations, high-intensity participants showed a stronger preference for jogging alone ( $M \mathrm{~s}=4.73 \mathrm{vs.} 4.05, p<.001)$, a finding that is inconsistent with the notion that high-intensity individuals will be more likely to seek out emotional stimulation from social interaction (Buss \& Plomin, 1975). Men also showed a higher preference for jogging than women $(M \mathrm{~s}=4.50 \mathrm{vs}$. $4.18, p<.05$ ), presumably because jogging might still be more likely to be a regular part of a man's daily lifestyle.

\section{Sensory Arousability Dimension}

The sensory arousal temperamental dimension replicated nicely in Study 3. High-intensity respondents showed a significantly higher level of enjoyment for "smelling the aroma of freshly baked bread" $(M s=6.84$ vs. $5.76, p<.0001)$ and "the fragrance of perfumes" $(M s=6.90$ vs. $5.68, p<.0001)$. Even 
TABLE 4

Lifestyle Measures Associated With Affect Intensity and Gender (Study 3)

\begin{tabular}{|c|c|c|c|c|c|c|c|}
\hline Lifestyle Measure & High $A I M$ & Low $A I M$ & $F$ & Male & Female & $F$ & $F A I M \times$ Gender \\
\hline 1. Watching exciting movies & 8.80 & $7.76 * * * *$ & $48.84 * * * *$ & 8.09 & 8.48 & .54 & 2.5 \\
\hline 2. Listening to romantic emotional music & 7.07 & $5.27 * * * *$ & $40.21 * * * *$ & 5.38 & $7.16^{* * * *}$ & $37.07 * * * *$ & .26 \\
\hline 3. Going on a date & 8.65 & $7.37 * * * *$ & $44.19 * * * *$ & 7.79 & 8.24 & .26 & .29 \\
\hline 4. Attending a major sporting event & 8.07 & $7.59 * * * *$ & $20.03 * * * *$ & 8.29 & $7.15^{* * * *}$ & $50.59 * * * *$ & $7.64 * * *$ \\
\hline 5. Watching exciting sports on TV & 7.18 & $6.89^{* * * *}$ & $12.59 * * * *$ & 7.68 & $6.12 * * * *$ & $63.14^{* * * *}$ & $7.67 * * *$ \\
\hline 6. Watching horror movies & 5.05 & $4.58 * * *$ & $7.10 * * *$ & 5.14 & $4.33^{* * * *}$ & $12.89 * * * *$ & .26 \\
\hline 7. Scary rides at amusement parks & 7.40 & $6.73 * * *$ & $9.00 * * *$ & 7.18 & $6.63^{*}$ & $3.90^{*}$ & 2.08 \\
\hline 8. Listening to news on the radio & 5.02 & 4.79 & 3.01 & 5.11 & $4.61 * * *$ & $6.89 * * *$ & 3.26 \\
\hline 9. Going to party with friends & 8.48 & $7.63 * * * *$ & $22.95 * * * *$ & 7.93 & $8.18 * * * *$ & .003 & .08 \\
\hline 10. Singing and dancing & 7.56 & $5.66 * * * *$ & $41.31 * * * *$ & 5.70 & $7.76^{* * * *}$ & $52.87^{* * * *}$ & .24 \\
\hline 11. Eating at restaurant with lots of friends & 8.76 & $7.66 * * * *$ & $38.31 * * * *$ & 7.80 & $8.72 * * * *$ & 19.53 & .85 \\
\hline 12. Reading quietly and leisurely & 6.41 & 6.14 & .004 & 5.89 & $6.80 * * * *$ & $12.72 * * * *$ & .08 \\
\hline 13. Bicycle riding alone & 5.53 & 5.29 & 1.23 & 5.44 & 5.34 & .52 & 2.09 \\
\hline 14. Jogging alone & 4.73 & $4.05^{* * *}$ & $8.58 * * *$ & 4.50 & $4.18^{*}$ & $3.81^{*}$ & .16 \\
\hline 15. Smelling aroma of freshly baked bread & 6.84 & $5.76 * * * *$ & $17.12 * * * *$ & 5.97 & $6.10^{*}$ & 3.61 & .01 \\
\hline 16. Smelling fragrance of perfumes & 6.90 & $5.68 * * * *$ & 20.44 & 5.81 & $6.88 * * * *$ & 11.73 & $3.21 * * * *$ \\
\hline
\end{tabular}

Note. $\quad N=541$. AIM $=$ Affect Intensity Measure.

${ }^{*} p<.05 .{ }^{* *} p<.01 .{ }^{* * *} p<.001 .{ }^{* * * *} p<.0001$.

more fascinating was the fact that women reported significantly higher levels of enjoyment of the sensory arousal they presumably experience from these two activities. A marginal Affect Intensity $\times$ Gender interaction was observed only for the smelling fragrances of perfumes, $F(1,314)=3.21, p<.07$.

\section{GENERAL DISCUSSION}

In general, most of the Study 2 findings were successfully replicated in Study 3, thus bolstering the reliability of the relation between affect intensity and the dimensions of temperament. However, certain inconsistencies in the results should be discussed. For example, with respect to the emotionality dimension, high- and low-intensity participants showed no significant differences in their enjoyment of horror movies in Study 2. However, in Study 3, high-intensity participants scored significantly higher than their low-intensity counterparts. On the one hand, it can be argued that the responses in Study 3 are consistent with arousal regulation theory that high-intensity people will seek out intense levels of emotional stimulation - both positive and negative (Larsen \& Diener, 1987). On the other hand, if the emotional arousal is too painful as in the findings of Study 1, high-intensity individuals should react by showing avoidance and distaste rather than enjoyment. Because horror movies and the thrill of scary rides are voluntarily selected and even paid for by consumers, it is more likely that high-intensity people do enjoy these extraordinary experiences. The case might be different when high-intensity consumers are involuntarily exposed to an advertising appeal displaying suffering and pain of a potential crime victim as in Study 1. More research is needed to clarify these issues.
Study 3 indicated that high-intensity participants showed a significantly higher level of enjoyment for "jogging alone." This is an unexpected result considering the fact that other low social interaction activities like "bike riding alone" and "reading quietly" replicated as predicted showing no significant affect intensity differences. On the other hand, lifestyle activities offering high levels of emotional and social stimulation (e.g., "partying" and "eating out with friends") replicated successfully in Study 3 with high-intensity respondents scoring higher than their low-intensity counterparts. These findings help to provide encouraging evidence of the validity of the relation between affect intensity and dimensions of temperament.

With respect to the sensory arousability dimension, the results seem to suggest that people (particularly women) with strong emotional temperaments tend to enjoy the sensory arousal experienced from olfactory stimuli such as the fragrance of favorite perfumes and the smell of delicious food. Because high-intensity participants also showed a preference for eating out with friends and grocery shopping, we have an emerging profile of a consumer who might be a favorable target for the food industry, the perfume industry, or any product or service where olfactory cues can be successfully used to stimulate desire.

\section{Future Research and Marketing Implications}

This study focused on dispositional affect intensity as a representation of temperament-the style with which an individual responds to a given stimulus or event. This characteristic style generalizes across the spectrum of emotions from negative (response to a burglar alarm ad in Study 1) to positive 
emotional experiences and lifestyle activities (represented in Studies 2 and 3). Using three studies, we attempted to show some level of consistency in the link between the temperamental characteristics of affect intensity and consumer lifestyles. However, more research is needed to strengthen the theoretical underpinnings linking affect intensity to other established measures of consumer lifestyles such as VALS and the LOV model (Kahle, Beatty, \& Homer, 1986). Future research should also determine the relation between affect intensity and gender, a measurable demographic variable. Although Diener et al. (1985) indicated that women are more likely to be elevated on the AIM than men, the findings in this article suggest that a situational approach to this relation might be more fruitful (Endler \& Rosenstein, 1997; Venkatraman, Marlino, Kardes, \& Sklar, 1990). For example, in Study 3 when the issue was a male-oriented activity (attending a major sporting event, watching sports on TV), an Affect Intensity $\times$ Gender interaction occurred with men scoring higher than women. In contrast, women scored higher than men resulting in an Affect Intensity $\times$ Gender interaction when the activity was more gender congruent such as "smelling the fragrance of one's favorite perfume."

If emotionality, sociability, sensory arousability, and activity level are dynamic dimensions of the affect intensity temperament, then future research should determine the extent to which certain profiles of consumers are susceptible to marketing stimuli designed to stimulate specific responses. For example, with respect to sensory arousability, will a marketing strategy highlighting the description of savory food (e.g., mouth-watering, appetizing, melted mozzarella cheese, oozing from a hot delicious pizza) stimulate higher levels of craving, desire, and purchase intentions from high rather than low affect intensity consumers? Furthermore, if gender differences play a significant role in dispositional affect intensity, what would be the implications of an Affect Intensity $x$ Gender interaction? That is, if women manifest stronger responses to sensory arousability cues, then women might be more vulnerable to marketing influence attempts highlighting olfactory cues for savory food. What, therefore, are the public policy implications?

Improved insight into the link between individual difference constructs and consumer behavior can serve not only as a basis for selecting market segments (Alwitt, 1991), but also for describing consumer segments with greater illumination and strategic insight.

\section{ACKNOWLEDGMENTS}

This article is dedicated to the memory of our beloved colleague Hong $\mathrm{C}$. Chen, who died in a drowning accident shortly after assisting in the data collection for Studies 1 and 2 . We are eternally indebted to his invaluable contribution. We also gratefully acknowledge the contribution of those who assisted in the production of the radio advertising spots:
Ray Young, the production engineer at radio station WUOM at the University of Michigan; and David Jeremy Moore (8-year-old son of David J. Moore), who acted as the child in the ad. Pamela Homer acknowledges the support of the California State University, Long Beach, Scholarly and Creative Activities Committee. The insightful comments of the editor and two anonymous reviewers on an earlier draft of the article are appreciated.

\section{REFERENCES}

Alwitt, L. F. (1991). Consumer personality characteristics can help guide marketing and creative strategies. Journal of Direct Marketing, 5, 39-47.

Bagozzi, R. P. (1994). ACR fellow speech. In C. T. Allen \& D. R. John (Eds.), Advances in consumer research (Vol. 21, p. 8). Provo, UT: Association for Consumer Research.

Bagozzi, R. P., \& Moore, D. J. (1996). The reliability and the structural components of affect intensity and need for cognition. Unpublished manuscript, School of Business, University of Michigan, Ann Arbor.

Barnes, G. E. (1976). Individual differences in perceptual reactance: A review of the stimulus-intensity-modulation individual difference dimension. Canadian Psychological Review, 17, 29-52.

Batra, R., \& Ray, M. L. (1986). Affective responses mediating acceptance of advertising. Journal of Consumer Research, 13, 234-249.

Berlyne, D. E. (1960). Conflict, arousal, and curiosity. New York: McGraw-Hill.

Buss, A. H., \& Plomin, R. (1975). A temperament theory of personality development. New York: Wiley.

Davis, M. H. (1983). Measuring individual differences in empathy: Evidence for a multidimensional approach. Journal of Personality and Social Psychology, 44, 113-126.

Diener, E., Sandvik, E., \& Larsen, R. J. (1985). Age and sex effects for emotional intensity. Developmental Psychology, 21, 542-546.

Digman, J. M., \& Shmelyov, A. G. (1996). The structure of temperament and personality in Russian children. Journal of Personality and Social Psychology, 71, 341-351.

Endler, N. S., \& Rosenstein, A. J. (1997). Evolution of the personality construct in marketing and its applicability to contemporary personality research. Journal of Consumer Psychology, 6, 55-66.

Eysenck, H. J. (1967). The biological basis of personality. Springfield, IL: Thomas.

Fiske, D. W., \& Maddi, S. R. (Eds.). (1961). Functions of varied experience. Homewood, IL: Dorsey.

Halvorson, C. F., Kohnstamm, G. A., \& Martin, R. P. (1994). The developing structure of temperament and personality from infancy to childhood. Hillsdale, NJ: Lawrence Erlbaum Associates, Inc.

Haugtvedt, C. P., Petty, R. E., \& Cacioppo, J. T. (1992). Need for cognition and advertising: Understanding the role of personality variables in consumer behavior. Journal of Consumer Psychology, 1, 239-260.

Hebb, D. O. (1955). Drives and the CNS (conceptual nervous system). Psychological Review, 62, 243-254.

Homer, P. M., \& Moore, D. J. (1998). The relationship between affect intensity and sensation seeking. Unpublished manuscript, University of Michigan, Ann Arbor.

Izard, C. E. (1977). Human emotions. New York: Plenum.

Kahle, L. R., Beatty, S., \& Homer, P. M. (1986). Alternative measurement approaches to consumer values: The List of Values (LOV) and Values and Lifestyles (VALS). Journal of Consumer Research, 13, 405-409.

Larsen, R. J. (1984). Theory and measurement of affect intensity as an individual difference characteristic. Dissertation Abstracts International, 85, 2297B. (University Microfilms No. 84-22112) 
Larsen, R. J., Billings, D. W., \& Cutler, S. E. (1996). Affect intensity and individual differences in informational style. Journal of Personality, 64, 185-207.

Larsen, R. J., \& Diener, E. (1987). Affect intensity as an individual difference characteristic: A review. Journal of Research in Personality, 21, 1-39.

Larsen, R. J., Diener, E., \& Emmons, R. A. (1986). Affect intensity and reactions to daily life events. Journal of Personality and Social Psychology, 51, 803-814.

Maddi, S. R. (1989). Personality theories: A comparative analysis (5th ed.). Chicago: Dorsey.

Mehrabian, A. (1979). Manual for the questionnaire measure of stimulus screening and arousability. Unpublished manuscript, Department of Psychology, University of California, Los Angeles.

Moore, D. J. (1995). Affect intensity and empathic emotions: An individual difference measure of advertising response. Journal of Marketing Communication, 1, 71-89.

Moore, D. J., \& Harris, W. (1996). Affect intensity and the consumer response to high impact emotional advertising appeals. Joumal of Advertising, 25,37-50.

Moore, D. J., Harris, W. D., \& Chen, H. C. (1995). Affect intensity: An individual difference response to advertising appeals. Journal of Consumer Research, 22, 154-164.

Petrie, A. (1967). Individuality in pain and suffering. Chicago: University of Chicago Press.

Raju, P. S. (1980). Optimum stimulation level: Its relationship to personality, demographics, and exploratory behavior. Journal of Consumer Research, 7, 272-282.
Richins, M. L. (1992). A consumer values orientation for materialism and its measurement: Scale development and validation. Journal of Consumer Research, 19, 303-316.

Steenkamp, J. E. M., \& Baumgartner, H. (1992). The role of optimum stimulation level in exploratory consumer behavior. Journal of Consumer Research, 19, 434-448

Stiff, J. B., Dillard, J. P., Somera, L., Kim, H., \& Sleight, C. (1988). Empathy, communication, and prosocial behavior. Communication Monographs, $55,198-213$.

Stout, P. A., \& Leckenby, J. D. (1986). Measuring emotional response to advertising. Journal of Advertising, 15, 35-42.

Strelau, J. (1982). Biologically determined dimensions of personality or temperament? Personality and Individual Differences, 3, 355-360.

Thomas, A., Chess, S., \& Birch, H. G. (1970). The origin of personality. Scientific American, 223, 102-109.

Venkatraman, M. P., Marlino, D., Kardes, F. R., \& Sklar, K. B. (1990). The interactive effects of message appeal and individual differences on information processing and persuasion. Psychology \& Marketing, 7, 85-96.

Zuckerman, M. (1979). Sensation seeking: Beyond the optimal level of arousal. Hillsdale, NJ: Lawrence Erlbaum Associates, Inc.

Accepted by Frank Kardes. 